\title{
The impact of down-regulated SK3 expressions on Hirschsprung disease
}

\author{
Gunadi $^{{ }^{*}} \mathbb{D}$, Mukhamad Sunardi ${ }^{1}$, Nova Yuli Prasetyo Budi ${ }^{1}$, Alvin Santoso Kalim ${ }^{1}$, Kristy Iskandar ${ }^{2}$ and \\ Andi Dwihantoro' ${ }^{1}$
}

\begin{abstract}
Background: Some Hirschsprung's disease (HSCR) patients showed persistent bowel symptoms following an appropriately performed pull-through procedure. The mechanism is presumed to be down-regulated small-conductance calcium-activated potassium channel 3 (SK3) expression in the HSCR ganglionic intestines. We aimed to investigate the SK3 expression's impact in HSCR patients after a properly performed pull-through surgery in an Indonesian population, a genetically distinct group within Asia.

Methods: We assessed SK3 gene expression in both the ganglionic and aganglionic colon of HSCR patients and controls colon by quantitative real-time polymerase chain reaction (RT-PCR).

Results: We ascertained fourteen sporadic HSCR patients and six anorectal malformation patients as controls. Quantitative RT-PCR showed that the SK3 expression was significantly lower (23-fold) in the ganglionic colon group compared to the control group ( $9.9 \pm 4.6$ vs. $5.4 \pm 3.4 ; p=0.044$ ). The expression of $S K 3$ in the aganglionic colon group was also significantly lower (43-fold) compared to the control group (10.8 \pm 4.4 vs. $5.4 \pm 3.4 ; p=0.015)$.

Conclusion: Our study shows that the down-regulated SK3 expression in ganglionic intestines might contribute to the persistent bowel symptoms following a properly performed pull-through surgery in Indonesian HSCR patients. Furthermore, this study is the first report of SK3 expression in a sample population of Asian ancestry.
\end{abstract}

Keywords: Appropriate pull-through, Hirschsprung disease, Indonesia, Persistent bowel symptoms, SK3

\section{Background}

Hirschsprung disease (HSCR: MIM\# 142623) is a neurodevelopmental disorder characterized by the absence of ganglion cells, resulting in a functional intestinal obstruction in infants. According to the type of aganglionosis, HSCR is classified as follows: shortsegment HSCR, long-segment HSCR, and total colon aganglionosis $[1,2]$. Its incidence differs among race with 15,21 , and 28 cases per 100,000 live births in European, African and Asian ancestry cases, respectively $[1,2]$. It might relate to the RET rs 2435357 susceptibility allele frequency difference across populations [3, 4]. Our previous studies supported this hypothesis since the frequency of rs2435357 variant in Indonesian ancestry

\footnotetext{
* Correspondence: drgunadi@ugm.ac.id

${ }^{1}$ Pediatric Surgery Division, Department of Surgery, Faculty of Medicine, Universitas Gadjah Mada/Dr. Sardjito Hospital, Yogyakarta 55281, Indonesia Full list of author information is available at the end of the article
}

cases is higher than those of European ancestry cases $(0.50$ vs. 0.25$)[5,6]$.

The current treatment for Hirschsprung disease (HSCR) is surgical resection of the aganglionic segment of the intestines. Most HSCR patients have a satisfactory outcome after a properly performed pull-through operation, however some patients continue to have persistent bowel symptoms such as constipation, soiling and enterocolitis. The cause of persistent bowel symptoms might be the transition zone pull-through or residual aganglionosis, but many have no identifiable cause for their ongoing bowel dysfunction $[7,8]$. The prevailing hypothesis is the down-regulated small-conductance calcium-activated potassium channel 3 (SK3) expression in ganglionic bowel in HSCR patients [9]. The SK3 channels have been shown to be involved in the outward currents activated by purines in the intact muscles in response to enteric inhibitory neurotransmission [10]. It is highly expressed in the platelet-derived growth factor receptor alpha-positive 
(PDGFRA+) cells [11], which together with interstitial cells of Cajal and smooth muscle cells regulate intestinal secretory activities and peristalsis [10]. In addition, a different genetic characteristic was previously revealed between the Indonesian and European populations with HSCR [12]. Therefore, we aimed to investigate the $S K 3$ expression in HSCR patients after a properly performed definitive surgery in an Indonesian population, a genetically distinct group within Asia.

\section{Methods}

\section{Subjects}

This cohort study was performed between August 2015 and July 2016 at Dr. Sardjito Hospital, Yogyakarta, Indonesia. The inclusion criteria were children with the age of $<18$ years old who have a diagnosis of HSCR based on clinical findings, contrast enema and histopathology, while the exclusion criteria were HSCR patients with low quality of total RNA. We used hematoxylin and eosin staining and S100 immunohistochemistry for histopathology assessment $[5,6,12-14]$.

The HSCR patients and controls were ascertained for this study after their parents signed a written informed consent form. The ganglionic and aganglionic intestinal specimens were collected at pull-through operation from HSCR patients, while control intestinal specimens were obtained at colostomy closure from anorectal malformation (ARM) patients. The ganglionic colon specimens were collected at least $10 \mathrm{~cm}$ above the transition zone. Intraoperative pathological evaluation was performed during pull-through procedure to ensure that the sample for RNA extraction is from aganglionic (or ganglionic) colon. The ARM patients were chosen as controls according to previous study [9].

The study was reviewed and approved by the Institutional Review Board of the Faculty of Medicine, Universitas Gadjah Mada/Dr. Sardjito Hospital, Indonesia (KE/FK/713/EC/2015).

\section{RET rs2435357 variant genotyping}

Genomic DNA samples of HSCR patients were genotyped for the RET rs2435357 variant using the PCR-RFLP method as described in our previous study [5].

\section{RNA extraction and quantitative RT-PCR}

Total RNA was isolated from 25 to $30 \mathrm{mg}$ of colon tissue using the total RNA Mini Kit (Tissue) (Geneaid Biotech Ltd., New Taipei City, Taiwan). The RNA was quantified by a NanoDrop 2000 Spectrophotometer (Thermo Scientific, Wilmington, DE, USA) and immediately stored at $-80^{\circ} \mathrm{C}$. The OD260/280 ratios typically range from 1.8 to 2.0 , indicating high RNA purity.

The SK3 expression was quantified using $100 \mathrm{ng}$ of total RNA, the Kapa SBYR Fast qRT-PCR One Step Kit Universal (Kapa Biosystems, Massachusetts, USA), and the BioRad
CFX Real-Time PCR System (California, USA). The SK3 primers were 5' - TGGACACTCAGCTCACCAAG-3' (forward) and 5'-GTTCCATCTTGACGCTCCTC-3' (reverse) [15]. Glyceraldehyde-3-phosphate dehydrogenase (GAPDH), a housekeeping gene, was used as an endogenous control. The GAPDH primers were 5'-GCACCGTCAAGGCTGAGAAC-3' (forward) and 5'-TGGTGAAGACGCCAGTG GA-3' (reverse). The Livak $\left(2_{\mathrm{T}}^{-\Delta \Delta \mathrm{C}}\right)$ method was utilized to determine the SK3 mRNA expression level in ganglionic and aganglionic colon from HSCR patients normalizing to $G A P D H$ and relative to ganglionic colon from control individuals [16].

\section{Statistical analysis}

Results were expressed as mean values $\pm \mathrm{SD}$. The analysis of $\mathrm{t}$-test was used to search for statistical differences between the two groups. A $p$ value less than 0.05 was considered statistically significant.

\section{Results}

During a 1-year period of study, we recruited 16 HSCR patients and eight controls according to the inclusion criteria. We excluded two HSCR patients and two controls because of their low quality of total RNA, thus, we further analyzed 14 HSCR patients and six controls. Neither familial nor syndromic HSCR patients were involved in this study.

According to degree of aganglionosis, $86 \%$ of patients have a HSCR short-segment. The mean age at diagnosis and definitive surgery was $10.1 \pm 31.6$ months and 20.4 \pm 35.9 months, respectively (Table 1). As for definitive surgery, 57\% HSCR patients underwent the transanal endorectal pull-through, followed by the Duhamel and Soave pull-through procedures in $29 \%$ and $14 \%$ children, respectively (Table 1 ).

First, we genotyped HSCR patients for the RET rs2435357 variant since this variant has been strongly associated with HSCR in an Indonesian population [5, 6]. The genotype frequencies for RET rs2435357 variant among HSCR patients were as follows: TT (12/14, 86\%), CT (0), and CC $(2 / 14,14 \%)$.

Quantitative RT-PCR showed that the SK3 expression was significantly lower (23-fold) in the ganglionic colon group compared to the control group $(9.9 \pm 4.6$ vs. $5.4 \pm 3.4$; $p=0.044$ ) (Fig. 1). The expression of $S K 3$ in the aganglionic colon group was also significantly lower (43-fold) compared to the control group $(10.8 \pm 4.4$ vs. $5.4 \pm 3.4 ; p=0.015$ ) (Table 2).

We followed-up all patients for a mean of $10.8 \pm$ 16.0 months following pull-through. Three individuals (patient 4, 6, and 11) developed enterocolitis in 5, 18, and 2 months, respectively, after pull-through, while only one subject (patient 6) suffered post-operative soiling (Table 1). 
Table 1 Clinical characteristics of Indonesian HSCR patients following definitive surgery and controls

\begin{tabular}{|c|c|c|c|c|c|c|c|}
\hline Patient & $\begin{array}{l}\text { Age at Diagnosis } \\
\text { (months) }\end{array}$ & $\begin{array}{l}\text { Type of } \\
\text { Aganglionosis }\end{array}$ & Colostomy & $\begin{array}{l}\text { Age at Definitive } \\
\text { Surgery (months) }\end{array}$ & $\begin{array}{l}\text { Definitive } \\
\text { Surgery }\end{array}$ & $\begin{array}{l}\text { Persisten Bowel } \\
\text { Symptoms }\end{array}$ & $\begin{array}{l}\text { RET rs2435357 } \\
\text { Genotyping }\end{array}$ \\
\hline 1 & $0-12$ & Long & Yes & $13-24$ & Duhamel & - & $\pi$ \\
\hline 2 & $0-12$ & Short & - & $0-12$ & TEPT & - & $C C$ \\
\hline 3 & $0-12$ & Short & - & $0-12$ & TEPT & - & $\pi$ \\
\hline 4 & $0-12$ & Short & - & $0-12$ & TEPT & Yes & $\pi$ \\
\hline 5 & $0-12$ & Short & Yes & $13-24$ & Soave & - & $\Pi$ \\
\hline 6 & $0-12$ & Short & Yes & $49-60$ & Duhamel & Yes & $\Pi$ \\
\hline 7 & 109-120 & Short & Yes & $121-132$ & Duhamel & - & $\pi$ \\
\hline $\begin{array}{l}8 \\
9 \\
10 \\
11 \\
12 \\
13 \\
14\end{array}$ & $\begin{array}{l}0-12 \\
0-12 \\
0-12 \\
0-12 \\
0-12 \\
0-12 \\
0-12\end{array}$ & $\begin{array}{l}\text { Long } \\
\text { Short } \\
\text { Short } \\
\text { Short } \\
\text { Short } \\
\text { Short } \\
\text { Short }\end{array}$ & $\begin{array}{l}\text { Yes } \\
- \\
\text { Yes } \\
- \\
- \\
- \\
-\end{array}$ & $\begin{array}{l}13-24 \\
0-12 \\
13-24 \\
0-12 \\
0-12 \\
0-12 \\
0-12\end{array}$ & $\begin{array}{l}\text { Soave } \\
\text { TEPT } \\
\text { Duhamel } \\
\text { TEPT } \\
\text { TEPT } \\
\text { TEPT } \\
\text { TEPT }\end{array}$ & $\begin{array}{l}- \\
- \\
- \\
\text { Yes } \\
- \\
- \\
-\end{array}$ & $\begin{array}{l}\Pi T \\
\Pi T \\
T T \\
\Pi T \\
T T \\
T \\
C C\end{array}$ \\
\hline Control & $\begin{array}{l}\text { Age at Stoma } \\
\text { Closure (months) }\end{array}$ & Diagnosis & & & & & \\
\hline 1 & 133-144 & ARM & & & & & \\
\hline 2 & $25-36$ & ARM & & & & & \\
\hline 3 & $13-24$ & ARM & & & & & \\
\hline 4 & $37-48$ & ARM & & & & & \\
\hline $\begin{array}{l}5 \\
6\end{array}$ & $\begin{array}{l}109-120 \\
13-24\end{array}$ & $\begin{array}{l}\text { ARM } \\
\text { ARM }\end{array}$ & & & & & \\
\hline
\end{tabular}

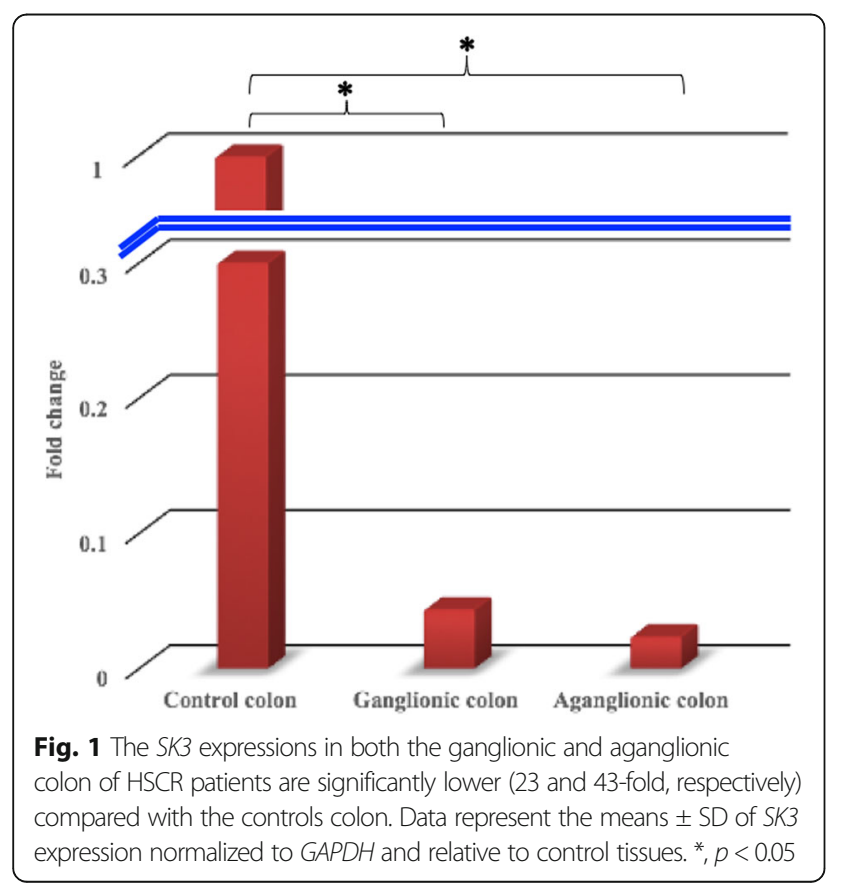

All symptoms resolved with rectal irrigations and administration of oral metronidazole.

\section{Discussion}

We describe new data on Indonesian HSCR patients which reveal a similar frequency of short-segment aganglionosis as reported in the literature $[17,18]$. Our study clearly demonstrates that the SK3 expression was strongly reduced in the HSCR patient intestines, both in the ganglionic and aganglionic bowel, compared to the control intestines. These findings are consistent with previous observations $[9,19]$. However, it should be noted that previous study [9] showed only half HSCR patients had reduced the SK3 expression. These differences might be attributed to the differences in the genetic background of analyzed population between previous report [9] versus our study.

Persistent bowel symptoms might occur in about 10\% of children following pull-through procedure. They

Table 2 The SK3 expression in both the ganglionic and aganglionic colon of HSCR patient and control colon

\begin{tabular}{lllll}
\hline SK3 & $\Delta \mathrm{C}_{\mathrm{T}} \pm \mathrm{SD}$ & $\Delta \Delta \mathrm{C}_{\mathrm{T}}(95 \% \mathrm{Cl})$ & Fold change & $p$-value \\
\hline Ganglionic colon & $9.9 \pm 4.6$ & $4.5(0.1-8.9)$ & 23 & $0.044^{*}$ \\
Aganglionic colon & $10.8 \pm 4.4$ & $5.4(1.2-9.7)$ & 43 & $0.015^{*}$ \\
Control colon & $5.4 \pm 3.4$ & & & \\
\hline
\end{tabular}

${ }^{*}, p<0.05$ is considered statistically significant for the SK3 expression difference between HSCR patient versus control colon 
range from constipation to severe episodes of abdominal distension, vomiting, and enterocolitis [20]. We eliminated the possibility of any residual aganglionosis in our patients with persistent bowel symptoms since we have performed intraoperative histopathological evaluations. There was no stricture identified in these patients after evaluation by a contrast enema.

It has been proposed that the down-regulated $S K 3$ in the HSCR colon results in unopposed cholinergic activity and a tonic hypercontraction, further causing a functional bowel obstruction in HSCR patients following pull-through [9]. Our study reveals a new evidence supporting this hypothesis by providing data from a genetically different population from previous reports $[9,19]$.

However, notably, the small sample size and limited power of the study, while a weakness of our report, implies that a significantly larger sample of patients needs to be involved to confirm our findings.

In this study, we involved the ARM patients as controls according to previous study [9]. It should be noted that most ARM patients suffer from a disturbance of the bowel motility [21]. Further study with more appropriate controls (e.g. trauma patients) is necessary to better clarify the impact of SK3 expression in the persistent bowel symptoms after a definitive surgery.

Furthermore, the molecular pathogenesis of HSCR still needs to be elucidated. It might involve the compromised condition of genes responsible for gangliogenesis of the enteric nervous system (ENS) [5, 6, 12, 22], the neurotransmitters expressed by the neurons of ENS $[11,23]$ and their interactions. Our results clarify the role of SK3 in the molecular pathogenesis of HSCR, particularly in Indonesia, a genetically distinct group within Asia $[4-6,12]$. It is important to note that the down-regulation in SK3 occurs in addition to other neurotransmitter signaling in HSCR. In addition, this study is the first report of $S K 3$ expression in a sample population of Asian ancestry. Moreover, our recent study shows that epistasis between RET and NRG1 is important to ENS development [6]. It might be necessary to determine the PDGFRA expression level as a control and a marker for the PDGFRA+ cells that express $S K 3$ for better understanding the persistence bowel symptoms' pathogenesis in HSCR patients following pull-through procedure. Unfortunately, we do not have any data on immunostaining of the resection segment for SK3 due to limitation of resources in our institution. Furthermore, most patients (86\%) in this cohort study carried the risk allele $(\mathrm{T})$ for HSCR that are consistent with our previous findings $[5,6]$.

This study may contribute to extending the knowledge on mechanisms causing the persistence of bowel symptoms after an appropriately performed pull-through. The possibility of the continuing intestinal symptoms after an appropriately definitive surgery should be explained during surgery counseling to HSCR parents. Furthermore, the pediatric surgery involves more than conducting an operation but consists of total care of the patient and the family, of which proper diagnosis, prognosis and counseling are fundamental parts of the performance of procedure and the patient recovery process.

\section{Conclusion}

Our study shows that the down-regulated SK3 expression in ganglionic intestines might contribute to the persistent bowel symptoms following a properly performed pullthrough surgery in Indonesian HSCR patients. Furthermore, this study is the first report of $S K 3$ expression in a sample population of Asian ancestry.

\section{Abbreviations \\ ARM: anorectal malformation; ENS: enteric nervous system; GAPDH: glyceraldehyde-3-phosphate dehydrogenase; HSCR: Hirschsprung disease; RT-PCR: real-time polymerase chain reaction; SK3: small-conductance calcium-activated potassium channel 3 .}

\section{Acknowledgements \\ We thank the patients and their families who have contributed in these studies. We are grateful to a native speaker at English Services Center, Faculty of Medicine, Universitas Gadjah Mada, for editing the grammar and proofreading of our manuscript. We are also thankful to the numerous nurses (Dr. Sardjito Hospital), Yuenleni and Sri Fatmawati (Faculty of Medicine, UGM) for technical assistance, Harini Natalia (Faculty of Medicine, UGM/Dr. Sardjito Hospital) for ethical clearance management, and Dian Nirmala Sirait, Wahyudhi Adriansyah, Taufik Indrawan, and all those who provided excellent technical support and assistance during the study.}

\section{Availability of data and material}

All data generated or analyzed during this study are included in the submission. The raw data are available from the corresponding author on reasonable request.

\section{Authors' contribution}

$\mathrm{G}, \mathrm{AD}$, and $\mathrm{Kl}$ conceived the study. $\mathrm{G}$ drafted the manuscript, and $\mathrm{AD}$ and $\mathrm{K}$ critically revised the manuscript for important intellectual content. MS, ASK, and NYPB facilitated all project-related tasks. All authors have read and approved the manuscript, and agreed to be accountable for all aspects of the work in ensuring that questions related to the accuracy or integrity of any part of the work are appropriately investigated and resolved.

\section{Funding}

This work was supported by a grant from the Faculty of Medicine, Universitas Gadjah Mada, Indonesia (Grant No. UPPM/72/M/05/04/04.15 to G. and A.D.).

\section{Ethics approval and consent to participate}

The Ethical Committee of Faculty of Medicine, Universitas Gadjah Mada/Dr. Sardjito Hospital gave approval for this study (KE/FK/713/EC/2015). The HSCR patients and controls were ascertained for this study after their parents signed a written informed consent form.

Consent for publication

Not applicable.

\section{Competing interests}

Dr. Gunadi is a member of the editorial board (Associate Editor) of this journal.The authors declare that they have no competing interests. 


\section{Publisher's Note}

Springer Nature remains neutral with regard to jurisdictional claims in published maps and institutional affiliations.

\section{Author details}

${ }^{1}$ Pediatric Surgery Division, Department of Surgery, Faculty of Medicine, Universitas Gadjah Mada/Dr. Sardjito Hospital, Yogyakarta 55281, Indonesia. 2Department of Child Health, Faculty of Medicine, Universitas Gadjah Mada/ UGM Academic Hospital, Yogyakarta 55291, Indonesia.

Received: 20 September 2017 Accepted: 31 January 2018 Published online: 13 February 2018

\section{References}

1. Chakravarti A, Lyonnet S. Hirschsprung disease. In: Scriver CR, Beaudet AL, Valle D, Sly WS, Childs B, Kinzler K, Vogelstein B, editors. The metabolic and molecular bases of inherited disease. 8th ed. New York: McGraw-Hill; 2001.

2. Amiel J, Sproat-Emison E, Garcia-Barcelo M, et al. Hirschsprung disease associated syndromes and genetics: a review. J Med Genet. 2008;45:1-14.

3. Emison ES, Garcia-Barcelo M, Grice EA, et al. Differential contributions of rare and common, coding and noncoding ret mutations to multifactorial Hirschsprung disease liability. Am J Hum Genet. 2010;87:60-74.

4. 1000 Genomes Project Consortium, Abecasis GR, Altshuler D, et al. A map of human genome variation from population-scale sequencing. Nature. 2010; 467:1061-73.

5. Gunadi, Dwihantoro A, Iskandar K, Makhmudi A. Rochadi. Accuracy of PCRRFLP for RET rs2435357 genotyping as Hirschsprung risk. J Surg Res. 2016;203:91-4

6. Gunadi, Kapoor A, Ling AY, et al. Effects of RET and NRG1 polymorphisms in Indonesian patients with Hirschsprung disease. J Pediatr Surg. 2014:49:1614-8.

7. Zimmer J, Tomuschat C, Puri P. Long-term results of transanal pull-through for Hirschsprung's disease: a meta-analysis. Pediatr Surg Int. 2016;32:743-9.

8. Menezes M, Pini Prato A, Jasonni V, et al. Long-term clinical outcome in patients with total colonic aganglionosis: a 31-year review. J Pediatr Surg. 2008;43:1696-9.

9. Coyle D, O'Donnell AM, Puri P. Altered distribution of small-conductance calcium-activated potassium channel SK3 in Hirschsprung's disease. J Pediatr Surg. 2015:50:1659-64.

10. Kurahashi $M$, Zheng $H$, Dwyer $L$, et al. A functional role for the 'fibroblastlike cells' in gastrointestinal smooth muscles. J Physiol. 2011; 589(Pt 3):697-710.

11. Kurahashi M, Nakano Y, Hennig GW, et al. Platelet-derived growth factor receptor alpha-positive cells in the tunica muscularis of human colon. J Cell Mol Med. 2012;16:1397-404.

12. Gunadi, Makhmudi A, Agustriani N. Rochadi. Effects of SEMA3 polymorphisms in Hirschsprung disease patients. Pediatr Surg Int. 2016;32:1025-8.

13. Setiadi JA, Dwihantoro A, Iskandar K, Heriyanto DS, Gunadi. The utility of the hematoxylin and eosin staining in patients with suspected Hirschsprung disease. BMC Surg. 2017;17:71.

14. Parahita IG, Makhmudi A, Gunadi. Comparison of Hirschsprung-associated enterocolitis following soave and Duhamel procedures. J Pediatr Surg. 2017; https://doi.org/10.1016/j.jpedsurg.2017.07.010.

15. Potier $M$, Joulin $V$, Roger $S$, et al. Identification of SK3 channel as a new mediator of breast cancer cell migration. Mol Cancer Ther. 2006;5:2946-53.

16. Livak KJ, Schmittgen TD. Analysis of relative gene expression data using real-time quantitative PCR and the 2(-Delta Delta C(T)) method. Methods. 2001;25:402-8.

17. Thakkar HS, Bassett C, Hsu A, et al. Functional outcomes in Hirschsprung disease: a single institution's 12-year experience. J Pediatr Surg. 2017:52:277-80

18. Langer JC. Hirschsprung disease. In: Coran AG, editor. Pediatric surgery. 7th ed. Philadelphia: Elsevier; 2012.

19. Piotrowska AP, Solari V, Puri P. Distribution of Ca2+-activated K channels, SK2 and SK3, in the normal and Hirschsprung's disease bowel. J Pediatr Surg. 2003;38:978-83.

20. Langer JC. Persistent obstructive symptoms after surgery for Hirschsprung's disease: development of a diagnostic and therapeutic algorithm. J Pediatr Surg. 2004:39:1458-62

21. Levitt MA, Peña A. Anorectal malformations. Orphanet J Rare Dis. 2007;2:33.
22. Alves MM, Sribudiani Y, Brouwer RW, et al. Contribution of rare and common variants determine complex diseases-Hirschsprung disease as a model. Dev Biol. 2013;382:320-9.

23. O'Donnell AM, Coyle D, Puri P. Decreased expression of NEDL2 in Hirschsprung's disease. J Pediatr Surg. 2016;51:1839-42.

\section{Submit your next manuscript to BioMed Central and we will help you at every step:}

- We accept pre-submission inquiries

- Our selector tool helps you to find the most relevant journal

- We provide round the clock customer support

- Convenient online submission

- Thorough peer review

- Inclusion in PubMed and all major indexing services

- Maximum visibility for your research

Submit your manuscript at www.biomedcentral.com/submit 